\title{
Culturally-Attuned Mentoring for Graduating Latina/o Social Workers to Foster Career Advancement
}

\author{
Nelly Rojas Schwan \\ Lirio K. Negroni \\ Annette Santiago-Kozmon
}

\begin{abstract}
The underrepresentation of Latinas/os in the social work profession, especially in higher levels of administration, has been amply documented. Successful Latina/o professionals can address the need for Latina/o leadership in the field by mentoring new graduates and supporting their development and career planning as they enter the professional world. This article presents an innovative mentoring program for Latina/o social work professionals conceptualized and led by the Latina/o Network of the Latina/o Network of the Connecticut chapter of the National Association of Social Workers (NASW). The program matches a Latina/o master's in social work graduating student with a senior Latina/o social work professional. The model of the mentoring program incorporates a coordinator, a liaison to each mentor-mentee dyad, a mentor-mentee developmental relationship, and group gatherings. A key aspect of the model is the attention to and inclusion of Latino cultural values of familismo, personalismo, confianza, and colectivismo, to foster the development of a sense of community. Empirical and anecdotal data illustrate the outcomes of the program. The implementation of the program, the lessons learned, and its applicability to other professionals and cultural groups are discussed.
\end{abstract}

Keywords: Mentoring, Latina/o professionals, Latino culture, career advancement, developmental relationships

The 2010 Census counted 50.5 million Latinas/os in the United States, making up $16.3 \%$ of the total population (Enis, Rios-Vargas, \& Albert, 2010). The nation's Latina/o population, which was 35.3 million in 2000 , grew $43 \%$ over the decade, and accounted for most of the nation's growth, (56\%) from 2000 to 2010 (Passel, Cohn, \& Lopez, 2011). It is projected that Latinas/os will total $29 \%$ of the U.S. population in 2050 due to immigration, migration, and high birth rates (Passel \& Cohn, 2008). According to the Pew Hispanic Center (Passel \& Cohn, 2008) Latinas/os will account for 60\% of the population growth between 2005 and 2050.

The Pew Hispanic Research Center reports that 37\% of Latinos currently living in the United States are foreign born (Patten, 2012). Like other immigrant groups, Latinas/os come to the United States seeking economic advancement and social mobility, and education is a recognized avenue to accomplish these aspirations. Like other immigrants, many Latinas/os want their children to have the opportunities they did not have such as

\footnotetext{
Nelly Rojas Schwan, Ph.D., LCSW, ACSW, is an Assistant Professor of Social Work in the School of Graduate and Professional Studies at the University of St. Joseph in West Hartford, CT. Lirio K. Negroni, Ph.D., LCSW is Associate Professor and Faculty in the Puerto Rican and Latino Social Work Studies Project of the University of Connecticut School of Social Work. Annette Santiago-Kozmon, MSW, LCSW, is an adjunct social work faculty member in the School of Graduate and Professional Studies at the University of St. Joseph and the director of Healing House of Connecticut. This work was supported by NASW, the University of St. Joseph, and the University of Connecticut.
} 
pursuing higher education. Also many Latina/o immigrants started their college education in Latin America and dream of completing their degrees in the states.

Historically, Latina/o students have been underrepresented and underserved in higher education (Fry, 2002; Schmidt, 2003). As of 2010, The Pew Hispanic Center reported significant growth in educational achievement among young Latinas/os, with 73\% of 1824 year olds completing high school and 44\% attending college (Fry, 2011). However, most of the increase in college attendance has been at community colleges. Of those completing high school and attending college, only 54\% of Latinas/os were enrolled in four-year colleges, compared with $73 \%$ of Whites, $78 \%$ of Asians, and $63 \%$ of Blacks (Fry, 2011).

The low enrollment of Latinas/os in four-year compared to two-year colleges indicates difficulties progressing to higher education. The 2010 American Community Survey of the U.S. Census Bureau documented the significant decrease in the percentage of higher levels of educational attainment with $62.2 \%$ Latinas/os earning a high school degree, $35.7 \%$ with an associate's degree or higher, $13 \%$ obtaining a college degree, and only 4.1\% completing a graduate or professional degree (U. S. Census Bureau, 2010).

The Latina/o college population includes a large number of first generation and immigrant adults most of whom are the first in their families to obtain a degree. While families in general are supportive of a family member pursuing education, they are not prepared to offer the support and guidance students need. In addition, families frequently do not anticipate the time demands of academic pursuits and may experience stress as a result (Cevallos, 2004).

It has been recognized that mentoring can be a source of support and guidance for students. According to Zalaquett , Gallardo, and Castellanos (2004), Latina/o students need role models to help them understand their educational opportunities and show them how to navigate the college system. Many schools offer programs focused on supporting students while in college. When graduates join the professional world they may find mentoring in the workplace, but there seems to be a scarcity of mentoring resources for new professionals as they prepare to enter the work force and transition from students to professionals, an important developmental process that requires career planning. They face challenges negotiating the higher education system, and continue to face challenges when they move into the professional world (Sólorzano, Villalpando, \& Oseguera, 2005).

As a minority group, Latinas/os encounter institutional and cultural racism (Hernandez, Carranza, \& Almeida, 2010), therefore it is very important to have role models and supporters who reflect the population, across political, economic, and social institutions. Social service organizations providing services to and employing people of color need people of color in supervisory, managerial, and leadership roles, including boards of directors, to achieve cultural competence. Latinas/os, the population with one of the highest percentages of poverty (Lopez \& Cohn, 2011), are high consumers of social work services, and social work institutions are pressed to increase their Latina/o bilingual staff at all levels of organization. However, the number of Latinas/os in supervisory positions or at higher levels of administration is very low (The Federal Hispanic Workgroup, 2008); an indication that the pace of professional advancement for 
this minority group is slow. As newcomers to the professional world, new Latina/o social workers need to develop networks of professional connections, be clear about their career goals, be realistic about the options available, and develop strategies for their own development. More privileged groups benefit from generations of networking, which constitutes social capital not available to Latinos. The lack of professional networks and limited focus on professional development can lead to poor choices, poor negotiation of employment conditions, dissatisfaction in employment, and changes in position arising from dissatisfaction with the job. Young professionals of color, Latina/os specifically, benefit from developing a strategy for advancement in order for their choices to become rungs in their career ladder.

This article presents an innovative mentoring program for Latina/o social work professionals. Conceptualized and led by the Latino Network of the Connecticut Chapter of the National Association of Social Workers (NASW), this program matches a graduating Latina/o master level social work student with a senior Latina/o social work professional. The Mentoring Program emerged as an avenue to support graduating Latinas/os entering the professional workforce or transitioning to more advanced positions.

\section{Literature Review}

\section{Mentoring}

Mentoring is defined as the relationship between an experienced professional and a novice, one that includes advising, guidance, and coaching focused on the personal and professional growth of the individual (Adams, 1998; Bogat, Liang, \& Rigol-Dahn, 2008; Zalaquett \& Lopez, 2006). It is based on the premise that a mentor and mentee engage in a series of interpersonal exchanges that are beneficial for both. Mentorship relationships may be formal or informal in nature. Formal mentoring is usually planned and established by a third party and has set goals, timelines, training, and structured activities. It is not surprising that at times a formal mentoring relationship evolves and becomes informal as mentors and mentees decide to cultivate and continue their relationship after the formal commitment ends and without the guidelines of the formal program (Zalaquett \& Lopez, 2006).

Career mentoring is specific to a mentor working with a mentee for the purposes of professional development and career growth. The qualities expected in a mentor include commitment to the role, acceptance of the mentee, ability to provide support, effective interpersonal skills, ability to communicate hope and optimism, and commitment to continuous learning (Zalaquett \& Lopez, 2006). The mentor has to be committed and must possess awareness of the responsibilities and skills embedded in the mentoring role.

Two types of mentoring, instrumental and psychological, occur simultaneously in an integrated manner (Laden, 2000; Luna \& Prieto, 2012). Instrumental mentoring refers to processes such as teaching, advising, coaching, advocating, and connecting with resources; while psychological mentoring includes emotional support and validation (Laden, 2000). Both types of mentoring help mentees enhance their self-esteem and sense 
of competence and efficacy (Laden, 2000). Studies document that integrated mentoring expands a mentees' network, sense of self-empowerment, and overall academic and career preparation (Luna \& Prieto, 2012). Crisp and Cruz (2012) distinguish four types of support: emotional, educational and career related, knowledge of academics, and role modeling.

\section{Mentoring as a Developmental Relationship}

The literature examines mentoring as a developmental relationship (Brown, Daly, \& Leong, 2009; Allen \& Finkelstein, 2003). Developmental relationships can contribute to individual growth and career advancement (Allen \& Finkelstein, 2003) and have been shown to have an association with career success (Gonzalez-Figueroa \& Young, 2005). A developmental focus, tailored to the developmental needs of the mentee, is essential to maximize the benefits of mentoring for both mentors and mentees (Brown et al., 2009). Mentoring of a new professional, thus, includes assisting in defining the professional self, exploring career options and opportunities, focusing on career development, setting realistic goals, and planning a path to achieve them.

Developmental relationships are mutual and reciprocal (Gutierrez, 2012; Pomeroy \& Steiker, 2011). While the relationship provides a professional developmental pathway for the mentee, it is also an opportunity for the mentor to grow and develop into more advanced roles and to make leadership contributions. Mentoring provides opportunities for professional enrichment which returns to the community as social capital. The mentors' work is sociopolitical in its nature as they assure, through the mentoring, that more Latinas/os and other underrepresented groups will gain visibility and access to power. Through networking and collaboration, Latina/os can get organized to become visible and influential, so they might represent their communities and advocate for their interests.

\section{Social Work and Mentoring}

Social work knowledge and skills are important for mentoring (Pomeroy \& Steiker, 2011). International experts have addressed the existing connections between social work and mentoring. Pehkonen, Arola, Zviyagina, and Grouev (2010) described mentoring as a process that can help senior social workers transfer their knowledge to new social workers, and in this way contribute to their professional growth and the strengthening of their professional identity. The authors stated that mentoring in the workplace allows new social workers to explore expectations, potentials, and qualifications, and decide whether those are aligned or in conflict with the agency's environment. According to the authors, "mentoring provides a forum for discussing the occupational welfare experienced in social work and the challenges emerging in it" (p. 24), and helps social workers cope effectively with occupational issues. They also stated that mentoring, at its optimal, can provide strength to an individual's professional identity, which includes the ability to be pliable in the workplace.

Gutierrez (2012) asserted that mentoring is a significant, but often overlooked, component of social work students' education, and frequently takes place "outside of 
formal courses and programs” (p. 1). The author stated that when students have positive mentors, they are more likely to do well in school, be more productive, have stronger professional skills, be more confident, and develop a larger professional network. She claimed that "mentoring students on any level can be a way to expand our knowledge of and to learn about different life experiences" (p. 2), and that faculty who mentor students benefit personally and professionally. In the case of field instructors, mentoring is one of the activities through which they provide expertise and facilitate students' learning of needed practice skills (Ortiz-Hendricks, Finch, \& Franks, 2005). However, this studentfield instructor mentoring relationship often ends as the student prepares to join the workforce.

\section{Culturally-attuned Mentoring}

It has been documented that demographic similarities between mentor and mentee contribute to the success of the relationship (Brown et al., 2009). Same-race relationships provide significantly more psychosocial support than cross-race relationships (Davis, 2006). For instance, having a Latino/a mentor can provide role modeling, cultural validation and pride (Rivera-Goba \& Nieto, 2007), and the meta-message that advancement as a Latina/o is possible.

Cultural differences can be a barrier to effective mentoring of racial and ethnic minority professionals. When a mentor and a mentee are from different cultural backgrounds, differences in attitudes and values may arise that can cause cultural miscommunications and conflict (Brown et al., 2009). Experienced professionals who have successfully navigated the challenges involved in career advancement are especially suited to offer culturally-attuned mentorship and support mentees' professional development. In the workplace, professionals of color may experience prejudice and racism ranging from overt racism to micro-aggressions, the often subtle comments reflective of prejudice, which are perceived as undermining by the receiver (Sue, 2010; Sue et al., 2007). The mentoring relationship becomes a safe environment when issues of racism, oppression, and micro-aggressions can be explored to validate the experience and identify strategies to respond in constructive ways.

Offering cultural affirmation is one of the most important goals of an ethnicallymatched mentoring relationship. Specifically, for Latina/o social workers new to the professional world, there are two distinct levels of bi-cultural exchanges: the socialization into the professional world and the ability to function in the predominantly White culture. Senior social workers of the same background who have successfully accomplished these developmental tasks can serve as role models and resources to new professionals (Thomas, 2006). It is important for Latino professionals new to the organizational culture to be mentored by other Latinos. Once they are confident negotiating the institutional culture, they can benefit from cross-cultural mentoring from higher level administrators. Kay and Wallace (2009) indicated that women and minority racial and ethnic groups may find themselves on the periphery of organizations and would benefit from cross-gender and cross-racial mentoring. This perspective is definitely applicable to Latina/o social workers, who often practice in organizations where high level administrators and board members are predominantly from the majority culture. However, it is important that they 
first gain comfort with the institutional culture to maximize the benefit of cross-cultural mentoring.

Mentoring programs for Latina/os increasingly incorporate a culturally-attuned focus. In order to be culturally-attuned, the program must pay special attention to the Latino cultural values of familismo, personalismo, confianza and colectivismo. Familismo is a "cultural value that stresses attachments, reciprocity, and loyalty...” (Andres-Hyman, Añez, Paris, \& Davidson, 2006, p. 696). The same authors referred to personalismo as a preference for relating on a personal rather than formal or institutional level. Because of familismo and personalismo values, Latinas/os in mentoring programs may value relationships based on genuine caring; may expect others in relationships to be open to sharing about themselves; and may prefer or expect close relationships. Development of confianza, an earned feeling of trust and familiarity and a feeling that the other person is worthy of their confidence is essential as mentors and mentees regard the other as a quasi-extended family member (Falicov, 2001). Colectivismo emphasizes activity for the benefit of the community rather than individual interests and needs (Zuñiga, 2001).

\section{The State NASW Latina/o Network Mentoring Program}

\section{NASW Latina/o Network}

The Latina/o Network of the Connecticut Chapter of the NASW started in 1997 with the mission to provide a professional network; to connect, support and recognize Latina/o social workers; to highlight the importance of culture in professional practice; and to advocate for the Latina/o population and social workers. Among the different efforts developed by the Network to address these goals has been the inclusion of mentoring opportunities for Latina/o social workers entering the career world. Given the demographic data on Latinas/os, population projections, and the data on educational attainment, the Network realized the importance of developing interventions to reverse the trend of losing Latina/o individuals along the pathway of education. Throughout the years, members of the Latina/o Network, a completely volunteer group, with the support of the Chapter's executive director, have been committed to this cause.

\section{The Mentoring Program}

The Network's interest in developing a mentoring program came from a desire to aid Latina/o students in the pursuit of higher education. In 2007 the Network reached out to local high schools, colleges, and universities to inquire about existing and needed support for Latina/o students. This effort identified a gap in support at the graduate level. Once a student graduated from their master's program, no support services were in place to aid in career advancement. This was reaffirmed in 2008 at a Connecticut NASW statewide conference when attendees to a workshop completed a survey regarding types of support social workers needed. Mentoring after graduation came up as a stated need.

The Mentoring Program functioned with senior social work volunteers who committed one year at a time to serve as mentors of graduating Latina/o MSW students. In 2009 the Latina/o Network launched the Mentoring Program with two mentor-mentee 
dyads. The program began with limited structure and no group activities, and the followup with mentors and mentees was done by the Network's chair utilizing formal letters and telephone contacts. In 2010 the program became more structured, with a designated coordinator, formal guidelines for matching, clearer expectations, and an evaluation component. The number of participating mentor-mentee dyads increased to four in 2010, seven in 2011, eight in 2012, and seven in 2013.

The purpose of the Mentoring Program was to provide support and guidance to recent Latina/o social work graduates to aid their transition to the professional world. The mentor was expected to: (1) help the mentee plan his/her future career goals and professional steps; (2) provide the mentee with knowledge of the professional world; (3) help the mentee explore ways he or she could be more successful; (4) facilitate the development of new professional networks for the mentee; (5) help the mentee transition into more advanced career levels as an MSW graduate; and (6) support the mentee in the exploration and negotiation of cross-cultural exchanges. The mentee was expected to: (1) use the mentoring relationship to focus on her/his professional development; (2) be receptive to what the mentor can offer; (3) be straightforward and honest and in consistent communication with the mentor; and (4) be open to change as part of her/his developmental process.

In addition to the expectations listed above, both mentors and mentees committed to (1) attend an Orientation Meeting; (2) determine ways in which they will keep in touch; (3) keep monthly contacts with each other; (4) coordinate at least two face-to-face activities; (5) participate in mentor-mentee gatherings coordinated by the Latina/o Network; (6) engage in a respectful, caring, and responsible relationship; (7) ask for assistance if they need help in their interactions; (8) inform the coordinator if for any reason they need to withdraw from the program; and (9) participate in the evaluation of the Mentoring Program.

The recruitment of mentors and mentees was done by the Network's members. The mentoring program was publicized in the state chapter's newsletter and through other events of the organization. Members of the Network reached out to the state's schools of social work and collaborated with the directors of student services to identify graduating Latina/o students. Those students were invited to an informational meeting and if interested, were given an application to become a mentee. Mentors were recruited through outreach at conferences, professional meetings and one-to-one contacts with successful professionals. The requirements for mentors included being a Latina/o with a minimum of five years of post-MSW experience and having the commitment to mentor. Those interested completed an application form that was used to match mentors and mentees according to interests, expectations, geographic location, strengths of mentors and expressed needs of the mentees.

\section{The Mentor-Mentee-Liaison Model}

The mentoring model developed by the Latina/o Network included a coordinator, a liaison to each mentor-mentee dyad, a mentor-mentee developmental relationship, and group gatherings. A key aspect of the model was the attention to and inclusion of Latino 
cultural values. The Mentoring Program was coordinated by a member of the Latina/o Network. Members of the Network served as liaisons to the mentor-mentee dyads. The responsibilities of the liaison were to: (1) act as a "bridge" between mentor and mentee; (2) be accessible when needed; and (3) have bi-monthly contact with the dyad to review progress and answer questions. Liaisons were an important component of the mentoring process because they helped facilitate the development of the mentoring relationship.

Developmental mentoring. There is a professional development process once social work students complete their master's degrees. The process involves preparing for licensing and then becoming a licensed practitioner. Some new professionals will move into supervisory positions and field instruction positions while others will use their practice experience to prepare to pursue doctoral education and teaching in community colleges and universities as adjunct instructors. Mentoring allows the mentee to prepare for that developmental process, as mentors have already passed through the developmental process or are in more advanced roles. Mentors help mentees become aware of professional options, discover their strengths and areas of further development, and strengthen their self-confidence in their ability to advance. The developmental pathway creates leaders within the profession.

Group gatherings. In addition to the one-to-one mentor-mentee communications and interactions, there were four all mentor-mentee-liaison group activities during the year and a special Latina/o Social Workers' Recognition Event, to which the mentoring program participants were invited as guests of honor. These activities were intended to prepare mentors and mentees for the mentoring experience and to facilitate relationshipbuilding and enhancement. They were planned to reflect the Latino cultural values of the group. For instance, in all events Latino food was included and group activities incorporated Latino music, decorations, etc. The group icebreakers encouraged personal sharing and were often connected to cultural identity and experiences of acculturation.

In the first gathering (Orientation Meeting), mentoring expectations were discussed and mentors and mentees were informed of who they were matched with. There was a training that included group activities to build relationships and to share prior experiences with mentors and mentoring, and an orientation about mentoring. The Network invited Latina/o social workers and allies to a special Latina/o Social Workers' Recognition event, which is usually celebrated in March, social work month. The purpose of the event was to recognize the contributions of Latina/o social workers from different fields of practice. The event was also an opportunity for the mentor-mentee dyads to socialize together and strengthen their relationships. This celebration enhanced professional and cultural identity pride and provided opportunities for networking.

The second gathering took place during the summer. This meeting served to celebrate mentees' graduation and transitioning to different jobs or career positions. Participants brought their parents, children and other relatives. The overall experience of connecting within the context of their families was a meaningful aspect of the Latino culture and strengthened the mentor-mentee-liaison connection.

The third gathering took place at the beginning of the fall. Mentors and mentees were invited to reflect on their developmental relationship. The group activities during this 
meeting were geared toward celebrating both mentors' and mentees' professional and personal accomplishments.

The final meeting, held in December, gave participants the opportunity to share their experiences and accomplishments and for the staff to highlight participants' contributions to the program.

\section{Three Years of Programming}

The mentees who have participated in this Mentoring Program have been immigrants/migrants or second generation Latinas/os and the first person in their family to complete a college education. Most of the mentors have had similar backgrounds. They may also have shared a common language. Their identification with traditional cultural values and beliefs, their experiences with immigration/migration, and their cultural identity and level of acculturation served as the context for their mentoring relationship to develop and grow.

When Latina/o mentees who are first generation college students start their higher education, they make two cultural transitions: to the majority culture and to the academic culture. Likewise, when they enter a new job as an MSW they encounter an organizational culture that may not operate based on their cultural values. They need to become bicultural, both to be able to maintain their Latino culture and function within the institutional environment. Talking with the mentor who has gone through these challenges helps the mentee realize "I am not the only one" and to respond to differences without thinking there is something wrong with him or herself.

\section{Specific Outcomes}

Both empirical and anecdotal data have been compiled in order to evaluate the Mentoring Program. Every year during the last meeting of the Program, participants completed a confidential questionnaire that combined open-ended, Likert-scale questions. The questionnaire explored respondents' thoughts regarding a mentee's career development and transition, the quality of the personal experience, and the success of the mentoring program.

More specifically, mentors and mentees were asked to indicate how much the mentoring program helped mentees (1) with career goals and professional steps; (2) to explore ways they could be more successful; (3) to transition from their role as student to that of a working professional; and (4) to develop networks. They indicated how much of the following were provided to the mentee: (1) knowledge of how the professional world operates; (2) knowledge of jobs, agencies, and populations that were good for them; and (3) guidance and support as they entered or re-entered the workforce. Additional Likertscale questions inquired about (1) how clear was the purpose of the mentoring program; (2) how much of an issue was time in establishing a mentor/mentee relationship; and (3) how much did time interfere with mentees ability to participate fully in the mentoring program.

Mentees also indicated how much they agreed or disagreed with the following: (1) It was important for me to meet a successful professional I could learn from; (2) Mentoring 
has helped me feel more confident as a Latina/o social worker; and (3) Mentoring has helped me value more my qualifications as a Latina/o social worker.

Mentors were asked how much they agreed or disagreed with these statements: (1) It was important for me to mentor a young Latina/o professional; (2) Mentoring has given me satisfaction and a sense of giving back; (3) Mentoring has helped me value much more my qualifications as a Latina/o social worker.

The open-ended questions required mentors and mentees to describe their experience; identify activities they did together; describe their level of comfort with the mentor/mentee relationship and what was lacking in the relationship; describe what the mentoring accomplished; and identify the gains and benefits along with areas for improvement.

\section{Questionnaire Findings}

A total of 20 respondents ( 9 mentees and 11 mentors) completed the questionnaire in the last three years (2009-2011). Although the number of respondents is small, the findings provided a preliminary impression of the usefulness of the program and the areas to be improved.

The findings suggested progress toward achieving the goals of the program. The overall experience was described as positive, enjoyable, encouraging and educational. The mentoring occurred through e-mails, phone calls and face-to-face contacts. In most instances mentors and mentees felt comfortable with their match and the relationship. Mentees reported increased self-confidence, self-awareness and appreciation of the networking opportunities. Areas identified for strengthening were same gender matching, frequency of face-to-face contact, and scheduling of time together. Table 1 presents the frequencies and percentages in the very much and somewhat categories for each of the following Likert-scale questions.

Table 1 Mentors' and Mentees' Responses to the Outcome Questions

\begin{tabular}{llccc}
\multicolumn{1}{c}{ QUESTIONS } & \multicolumn{2}{c}{ Mentees } & \multicolumn{2}{c}{ Mentors* } \\
\multicolumn{1}{c}{ How much does the mentoring... } & $f$ & $\%$ & $f$ & $\%$ \\
\hline Help mentee with career goals & 9 & $100 \%$ & $7(\mathrm{n}=9)$ & $78 \%$ \\
Provide mentee knowledge prof. world & 9 & $100 \%$ & $9(\mathrm{n}=10)$ & $90 \%$ \\
Help mentee explore ways to success & 6 & $67 \%$ & $7(\mathrm{n}=10)$ & $70 \%$ \\
Provide knowledge of jobs, agencies & 6 & $67 \%$ & $8(\mathrm{n}=11)$ & $73 \%$ \\
Help transition from student to professional & 7 & $78 \%$ & $8(\mathrm{n}=10)$ & $80 \%$ \\
Help mentee develop networks & 5 & $56 \%$ & $6(\mathrm{n}=10)$ & $60 \%$ \\
Provide mentee guidance & 8 & $89 \%$ & $8(\mathrm{n}=11)$ & $73 \%$ \\
\hline *The total number of respondents varied per question in the mentors' column and percentages were \\
calculated based on that number.
\end{tabular}


All mentees felt that the program helped them with career goals and knowledge of the professional world. Slightly more than half of the mentees indicated the program helped them to develop networks. This item had the lowest score for mentors and mentees and may reflect that for many of the dyads, communication was via e-mail and phone, which provided less opportunity for the social interaction involved in networking.

Table 2 displays the frequencies and percentages in the very much and somewhat categories for each of the Likert-scale questions about participation in the Mentoring Program.

Table 2 Mentors' and Mentees’ Responses Regarding Participation in the Program

\begin{tabular}{|c|c|c|c|c|}
\hline \multirow[t]{2}{*}{$\begin{array}{c}\text { QUESTIONS } \\
\text { Indicate whether ... }\end{array}$} & \multicolumn{2}{|c|}{$\begin{array}{c}\text { Mentees } \\
\mathrm{N}=9\end{array}$} & \multicolumn{2}{|c|}{$\begin{array}{l}\text { Mentors* } \\
\mathrm{N}=11\end{array}$} \\
\hline & $f$ & $\%$ & $f$ & $\%$ \\
\hline The purpose of the program was clear & 9 & $100 \%$ & $11(\mathrm{n}=11)$ & $100 \%$ \\
\hline Time was an issue for relationship to develop & 6 & $67 \%$ & $9(\mathrm{n}=11)$ & $82 \%$ \\
\hline Time interfered with participation in the program & 7 & $78 \%$ & $5(\mathrm{n}=10)$ & $50 \%$ \\
\hline
\end{tabular}

The purpose of the program was clear to all participants. However, time was an issue that affected the development of the relationship and participation in the program. For the majority of the mentors, time was an issue for developing the relationship; and for the mentees, time was an issue for participating in the program. Table 3 presents the results of the combined strongly agree and agree responses about mentees' professional gains.

Table 3 Mentees’ Responses on Professional Gains

\begin{tabular}{lcc}
\hline \multicolumn{1}{c}{ QUESTIONS } & \multicolumn{2}{c}{ Mentees } \\
& \multicolumn{1}{c}{$\mathrm{N}=9$} \\
& $f$ & $\%$ \\
\hline It was important to meet a successful professional I could learn from & 9 & $100 \%$ \\
Mentoring helped me feel more confident as a Latina/o social worker & 6 & $67 \%$ \\
Mentoring helped me value my qualifications as a Latina/o social worker & 6 & $67 \%$ \\
\hline
\end{tabular}

Mentees were in full agreement that it was important for them to meet a successful professional from whom they could learn. Even though the majority (67\%) felt that it had helped them feel more confident and valued, the impact of these aspects on professional self-esteem was not as strong as the authors had anticipated. Table 4 presents the results of the combined strongly agree and agree responses about mentors' professional gains. 
Table 4 Mentors’ Responses on Professional Gains

\begin{tabular}{lcc}
\hline \multicolumn{1}{c}{ QUESTIONS } & \multicolumn{2}{c}{ Mentors } \\
& $f$ & $\mathrm{~N}=11$ \\
\hline It was important for me to mentor a Latina/o professional & 10 & $91 \%$ \\
Mentoring gave me satisfaction and a sense of giving back & 9 & $82 \%$ \\
Helped me value my qualifications as a Latina/o social worker & 9 & $82 \%$ \\
\hline
\end{tabular}

The mentors' response indicated a high level of satisfaction with the experience, with the satisfaction of giving back, and an increased professional self-esteem. The sharing of mentoring experiences that occurred in the first meeting triggered recognition and memories of their own mentors, and having the opportunity to mentor another Latina/o to give back to the next generation, met the mentors' developmental need of contributing and nurturing others.

The findings of this evaluation have provided valuable feedback that has been used to modify and enhance the quality of the program. Given the small size of the sample, the variation in the data collection process and the early developmental stage of the program, these findings must be taken cautiously and cannot be used to make generalizations.

\section{Discussion Groups' Comments}

At the fall and December meetings mentors and mentees were encouraged to share their experiences of the program. Their comments are presented next and have been organized around the following themes:

Ethnic/cultural connections. While there was great diversity in their country of origin, the dyads felt connected as Latina/os and shared a sense of responsibility for their ethnic community. Mentors felt they were helping launch the new generation of Latina/o professionals who will continue their work, "passing on the baton." One mentor expressed that he felt that mentoring had a ripple effect and made the analogy to a pebble thrown in the water.

The mentees felt they had somebody who understood their experience and represented a resource they did not have in their families. A mentor expressed: "I was a single mother going to school so I know what ...my mentee experiences. I have sons, and mentoring a female has made the connection very strong...it is like mothering a professional." The mentees repeatedly commented that they were the first in their families to go to college and graduate school. A mentee shared how deflated she felt after a negative job interview and how the mentor was there to "hold" her, help her reflect on what went wrong, learn from the experience, and prepare for the next interview.

In line with cultural values of familismo and personalismo the mentoring relationship often went beyond the strictly professional focus and took an interest in the mentee and in the mentee's family. A mentee commented that early in the mentoring year she had been 
hospitalized for a heart problem and her mentor called her everyday "just to tell you that I am thinking of you and hoping for your recovery." The mentee added, “...that meant the world to me and I think it contributed to my recovery." A mentor of two consecutive years indicated that she had developed very close relationships with her mentees and she knew they would always have a special relationship. There was agreement when a mentee indicated that her experience with her mentor was "like having a second parent."

The value given by mentors and mentees to the group gatherings highlighted the importance of colectivismo which supported the creation of a community among all program participants. Including family members in social activities reflected the consideration of familismo and strengthened the mentor-mentee connection. Having everyone share their experiences with mentoring, their professional histories, how they have arrived to their present positions, and something personal in the Orientation Meeting reflected personalismo and served to build confianza. The sharing of food in the activities contributed to informal exchanges and community building.

Having a liaison. The liaison functioned as a back-up and monitored the relationship. Participants' comments indicated that once the relationship developed, the liaison was no longer needed. However, for some mentees, having the liaison meant that "there was another person who cared... and it made me feel more valued." Having one person specifically assigned to one dyad, as opposed to having a coordinator assigned to all dyads, had some benefits. It ensured more personal, frequent and intimate connections within the mentor-mentee dyad and thus more possibilities for the mentoring to succeed.

Professional growth. The mentoring offered a range of support, from addressing immediate needs and skill development to engaging in long-range planning. Mentees felt understood, supported and encouraged to advance. They reported growth in their job application, interviewing, and negotiation skills. A mentee expressed that when she felt she had reached her goal, the mentor challenged her and said, "No... there is a ladder you can climb." The mentee realized that she needed to change jobs to pursue employment that could provide opportunities to reach this new goal and was encouraged to take the next step of licensing. Another mentee credited her mentor with helping her find strength to develop her skills: "I had never spoken in public and with the encouragement of my mentor, I spoke in a panel, and discovered such strength in myself; I received terrific feedback and now I know that I can do this and more."

For the Latina/o Network members developing the Program there has also been satisfaction and growth. Every mentoring activity led to the development of human capital among the Latina/o professionals through training, education, knowledge and skills; (Turner De Tornes et al., 2013) and to the appreciation of the mentors and mentees. The mentors have been generous to give of themselves to nurture new professionals; and the mentees have been willing to trust and explore their fears and insecurities. It is reassuring to know that there are more social workers prepared and committed to serve the community, and that the two groups combined are contributing "nuestro granito de arena" (our grain of sand) to make it happen.

The spirit of the Mentoring Program is reflected in the following quote by a mentee: "I would like to express my appreciation of the program and my mentor...[who] has been 
amazing and continues to mentor me. I am truly thankful and blessed that I have had the opportunity to meet such an amazing individual and am certain she will continue to touch the lives of those whom she meets and mentors."

\section{Applicability of the Mentoring Program}

This Mentoring Program represents a contribution to the field of mentoring because of its focus on Latinas/os and the career of social work. The program validates the importance of mentoring programs attuned to the cultural experiences and values of Latina/os. While there is scarcity in the literature about mentoring programs for graduate level students transitioning to the professional world, the authors propose that this program can be used with graduate students in other disciplines and other cultural backgrounds. Experiences in other disciplines confirm the value of mentoring to support graduate professionals for successful career development (Rivera-Goba \& Nieto, 2007; Williams-Nickelson, 2009). Specific recommendations for mentoring programs for professionals include consideration of demographics, i.e. gender, racial, and ethnic background in matching dyads; and inclusion of activities reflective of the culture when developing programs for specific cultural groups. Programs should also consider the importance of a liaison to sustain the mentors and mentees' energy and commitment to the relationship.

This mentoring program can be replicated with the sponsorship of an agency or a professional organization. It requires committed staff or volunteers who have allocated time to coordinate the program. There is need to develop a connection with the schools of social work and the professionals of the ethnic community identified for the mentoring program. Planning and implementation of the program needs to incorporate the cultural values of the particular ethnic group. The costs are minimal but essential to develop materials for recruitment and supplies for group gatherings. Possible challenges include time demands and a need for continuous recruitment of mentors and liaisons. However, hearing about the gains for mentors and mentees and experiencing the success of the program is rewarding and generates the energy for all involved. So far, the program has offered mentoring to 20 graduating MSW students and has involved 11 mentors. It is becoming known in the community, thus increasing awareness of the benefits of mentoring and networking among young Latina/o professionals.

\section{References}

Adams, H. G. (1998). The mentorship briefing guide: Handbook for establishing and implementing a mentoring program. South Bend, IN: Gem Consortium.

Allen, T., \& Finkelstein, L. M. (2003). Beyond mentoring: Alternative sources and functions of developmental support. The Career Developmental Quarterly, 51(4), 346-355.

Andres-Hyman, R. C., Ortiz, J., Añez, L. M., Paris, M., \& Davidson, L. (2006). Culture and clinical practice: Recommendations for working with Puerto Ricans and other Latinas(os) in the United States. Professional Psychology: Research and Practice, 37(6), 694-701. 
Bogat, G. A., Liang, B., \& Rigol-Dahna, R. M. (2008). Stages of mentoring: An analysis of an intervention for pregnant and parenting adolescents. Child and Adolescent Social Work Journal, 25(4), 325-341.

Brown, R. T., Daly, B. P., \& Leong, F. L. (2009). Mentoring in research: A developmental approach. Professional Psychology: Research and Practice, 40(3), 306-313. doi:10.1037/a0011996

Cevallos, R. (2004). From barrios to Yale: The role of parenting strategies in Latino families. Hispanic Journal of Behavioral Sciences, 26(2), 171-186.

Crisp, G., \& Cruz, I. (2012). Confirmatory factor analysis of a measure of "mentoring” among undergraduate students attending a Hispanic serving institution. Journal of Hispanic Higher Education, 9(3), 232-244.

Davis, T. (2006). The impact of race on manager's experiences of developmental relationships: An intra-organizational study. Journal of Organizational Behavior, 11(6), 479-492. doi:10.1002/job.40301106

Enis, S. R., Rios-Vargas, M., \& Albert, N. C. (2010). The Hispanic Population 2010. Retrieved from http://www.census.gov/prod/cen2010/briefs/c2010br-04.pdf

Falicov, C. J. (2001). The cultural meanings of money: The case of Latinos and AngloAmericans. American Behavioral Scientist, 45(2), 313-328.

Fry, R. (2002). Latinos in Higher Education: Many enroll, too few graduate. Washington, DC: Pew Hispanic Center. Retrieved from http://www.pewhispanic.org/2002/09/05/latinos-in-higher-education/

Fry, R. (2011). Hispanic College Enrollment Spikes, Narrowing Gaps with Other Groups. Washington, DC: Pew Hispanic Center. Retrieved from http://www.pewhispanic.org/2011/08/25/hispanic-college-enrollment-spikesnarrowing-gaps-with-other-groups/

Gonzalez-Figueroa, E., \& Young, A. M. (2005). Ethnic identity and mentoring among Latinas in professional roles. Cultural Diversity and Ethnic Minority Psychology, 11(3), 213-226. doi:10.1037/1099-9809.11.3.213

Gutierrez, L. (2012). From the editor: Recognizing and valuing our roles as mentors. Journal of Social Work Education, 48(1), 1-4.

Hernandez, P., Carranza, M., \& Almeida, R. (2010). Mental health professionals' adaptive responses to racial micro-aggressions: An exploratory study. Professional Psychology: Research and Practice, 41(3), 202-209.

Kay, F., \& Wallace, J. E. (2009). Mentors as social capital: Gender, mentors, and career rewards in law practice. Sociological Inquiry, 79(4), 418-451.

Laden, B. V. (2000). The Puente project: Socializing and mentoring Latino community college students. The Free Library. Retrieved from http://www.thefreelibrary.com/The Puente Project: Socializing and Mentoring Latino Community...-a065805521 
Lopez, M. H., \& Cohn, D. (2011). Hispanic poverty rate highest in new supplemental census measure. Washington, DC: Pew Hispanic Center of the Pew Research Center. Retrieved from http://www.pewhispanic.org/files/2011/11/148.pdf

Luna, V., \& Prieto, L. (2012). Mentoring affirmations and interventions: A bridge to graduate school for Latina/o students. Journal of Hispanic Higher Education, 8(2), 213-224.

Ortiz-Hendricks, C., Finch, J. B., \& Franks, C. L. (2005). Learning to teach, teaching to learn: A guide for social work field education. Alexandria, VA: CSWE Press.

Passel, J., \& Cohn, D. V. (2008). U.S. Population Projections: 2005-2050. Washington, DC: Pew Hispanic Research Center. Retrieved from http://www.pewhispanic.org/2008/02/11/us-population-projections-2005-2050/

Passel, J., Cohn, D. V. \& Lopez, M. H. (2011). Census 2010: 50 million Latinos. Hispanics account for more than half of the nation's growth in past decade. Washington, DC: Pew Hispanic Research Center. Retrieved from http://www.pewhispanic.org/2011/03/24/hispanics-account-for-more-than-half-ofnations-growth-in-past-decade/

Patten, E. (2012). Statistical portrait of the foreign-born population in the United States, 2010. Washington, DC: Pew Hispanic Research Center. Retrieved from http://www.pewhispanic.org/2012/02/21/statistical-portrait-of-the-foreign-bornpopulation-in-the-united-states-2010/\#6

Pehkonen, A., Arola, M., Zviyagina, O., \& Grouev, A. M. (Eds.). (2010). Mentoring and social work: Mentoring handbook. Helsinki, Poland: University Print. Retrieved from http://www.julkari.fi/bitstream/handle/10024/80078/31ed8f03-8e0b-4925-89c08ba244b68354.pdf?sequence $=1$

Pomeroy, E., \& Steiker L. (2011). Paying it forward: On mentors and mentoring. Social Work, 56(3), 197-199.

Rivera-Goba, M. V., \& Nieto, S. (2007). Mentoring Latina nurses: A multicultural perspective. Journal of Latinos \& Education, 6(1), 35-53. doi:10.1207/s1532771xjle0601_3.

Schmidt, P. (2003). Academe's Hispanic future. The Chronicle of Higher Education. Retrieved from http://chronicle.com/article/Academes-Hispanic-Future/20497/

Sólorzano, D. G., Villalpando, O., \& Oseguera, L. (2005). Educational inequities and Latina/o undergraduate students in the United States: A critical race analysis of their educational progress. Journal of Hispanic of Higher Education, 4(3), 272-294. doi: $10.1177 / 1538192705276550$

Sue, D. W. (2010). Microaggressions in everyday life. Race, gender, and sexual orientation. Hoboken, NJ: Wiley. 
Sue, D. W., Capodilupo, C. M., Torino, G., Bucceri, J. M., Holder, A. M. B., Nadal, K., \& Esquilin, M. (2007). Racial microaggressions in everyday life: Implications for clinical practice. American Psychologist, 62(4), 271-286.

The Federal Hispanic Workgroup. (2008). Report on the Hispanic Employment Challenge in the Federal Government: The Executive Summary. Washington, DC: Author. Retrieved from http://www.eeoc.gov/federal/reports/hwg.html

Thomas, D. A. (2006). The impact of race on managers' experiences of developmental relationships (mentoring and sponsorship): An intra-organizational study. Journal of Organizational Behavior, 11(6), 479-492.

Turner De Tornes, L., Allen, T. D., Hoffman, B. J., Baranik, L. E., Sauer, J. B., Baldwin, S., ... \& Evans, S. C. (2013). An interdisciplinary meta-analysis of the potential antecedents, correlates, and consequences of protégé's perceptions of mentoring. Psychological Bulletin, 139(2), 441-476. doi: 10.1037/a0029279

U. S. Census Bureau. (2010). Selected population profile in the United States: 2010 American community survey 1-year estimates. Retrieved from http://factfinder2.census.gov/bkmk/table/1.0/en/ACS/10 1YR/S0201//popgroup 001 $\underline{002|004| 012 \mid 400}$

Williams-Nickelson, C. (2009). Mentoring women graduate students: A model for professional psychology. Professional Psychology: Research and Practice, 40(3), 284-291.

Zalaquett, C. P., Gallardo, M. E., \& Castellanos, J. (2004). The National Successful Latina/o Student Project: Providing Role Models to Latina/o Students. Retrieved from http://www.coedu.usf.edu/zalaquett/s/p.html

Zalaquett, C. P., \& Lopez, A. (2006). Learning from the stories of successful undergraduate Latina/Latino students: the importance of mentoring. Mentoring \& Tutoring, 14(3), 337-335. doi: 10.1080/13611260600635563.

Zuñiga, M. E. (2001). Latinos: Cultural competence and ethics. In R. Fong \& S. Furuto (Eds.), Culturally competent practice: Skills, interventions, and evaluations (pp. 4760). Boston, MA: Allyn and Bacon.

\section{Author note:}

Address correspondence to: Nelly Rojas Schwan, Ph.D., School of Graduate and Professional Studies, The University of St. Joseph, 1678 Asylum Avenue, West Hartford, CT 06117-2791. Email: nschwan@usj.edu. 